\title{
Effect of Training and Job Satisfaction on Employees Performance and Company Performance in Support to Achieve the Internationalization Model of SME's Competitive Advantage
}

\author{
INDI DJASTUTI ${ }^{1)}$, MAHFUDZ ${ }^{2)}$, DARYONO ${ }^{3)}$, LELA LESTARI $^{4)}$ \\ 1,2,3 Faculty of Economics and Business, Diponegoro University, Semarang, INDONESIA \\ ${ }^{4}$ Vocational School, Diponegoro University, Semarang, INDONESIA
}

\begin{abstract}
Efforts preparation of models and strategies used to improve the competitiveness of creative industries in the conduct of internationalization, especially in the ASEAN Economic Community (AEC), which has been produced in the study the first year has been done by connecting the variable performance Small and Medium Industries (SMI) with variable internationalization of SMEs and network resources. SEM Statistical test results showed that the performance of SMEs is not affected by the internationalization variable, meaning that international business activities have not been carried out intensively characterized by the limited scope of operation of the international market and the low level of sales profits. SME performance is affected by network resources' ability to utilize network resources is important for SMEs to access international resources, knowledge and market opportunities. Internationalization low level and the need for the utilization of network resources, making this study in the second-year concentrates on the manufacture of the modules to be tested on a group of SMEs surveyed, with an emphasis of matter related to the knowledge of the creative industry in general and specifically in Kendal District. Knowledge of import-export and knowledge of the Indonesian Export Financing Agency and knowledge about running a business based on digital. Modules that have been prepared are then used to test the SMI group of 145 SMEs. Furthermore, the results of training are evaluated and the results are significantly increased knowledge of the materials that have been given. Other than that, also linked variable influence on the performance of workers' training and performance of SMEs. Based on the increase in importexport knowledge possessed by SMEs in Kendal district is expected competitiveness of creative industries in Kendal increases which in turn will be able to face the AEC.
\end{abstract}

Key-Words: - training; knowledge; SME performance; job satisfaction; competitive advantage; internationalization; AEC; company performance

Received: November 2, 2019. Revised: April 7, 2020. Accepted: April 12, 2020. Published: April 30, 2020.

\section{Introduction}

Described the results of research in Kendal SMEs through the selected sample of 145 companies in the garment and fashion industry group is the largest industry (47\%), which produces a variety of products such as clothing Muslim, praying tools, batik clothing, embroidered clothing, and shirts. Followed by the companies included in the category of craft and jewelry made from raw materials such as rattan, leather, wood, bamboo, batik, mendoan, pandan, natural stone, silver, and ceramics. Judging from the number of workers, most companies have a workforce of between 21-99 people $(64 \%)$, and the rest has a workforce of between 5-20 people. Based on the total workforce of the Directorate General of Small and Medium Industry of the Ministry of Industry of Indonesia
(2009: 1-3) determined that the criteria for small industrial groups are a company with 5-20 employees and 21-99 for the secondary industry. On the basis of these criteria, most of the samples in this study are secondary industry group and the rest are small industrial groups.

In terms of total annual sales, the majority (41\%) ranges between $\mathrm{Rp} 200$ million to $\mathrm{Rp} 2.5$ billion. The study identified the existence of companies with total sales of $\mathrm{Rp} 2.6$ billion to Rp 50 billion, which is dominated by companies with sales ranging from $\mathrm{Rp} 2.6$ billion to $\mathrm{Rp} 12.5$ billion $(25 \%)$. Furthermore, when viewed in terms of experience in the industry, most companies (63\%) have more than 5 years of experience, including those dominated by companies with experience of 6 years to 20 years. Experience is an important basis 
for preparing to expand its business in both domestic and international markets. Internationalization is a "closed-loop", ie previous experience is a guarantee for the next step. Other than that, there are companies that operate a maximum of 5 years $(26 \%)$. From these findings, it is known that there are some companies that do international business rapidly. The results of interviews reveal that there are some fast SME entrepreneurs working in the international market and to prioritize export markets rather than the domestic market with huge market potential. Table 1 shows the international activities of SMEs in Kendal.

Table 1. International Activities of SMEs in Kendal

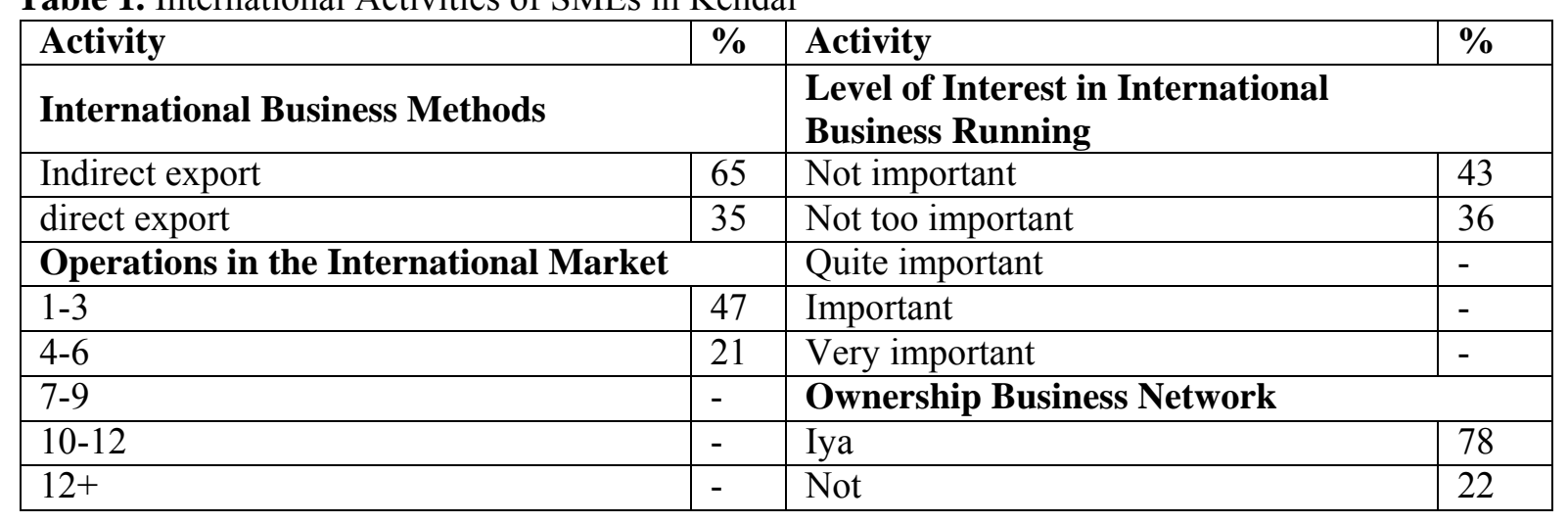

For most SMEs, entrepreneurs tend to judge a major international business due to huge market potential and the possibility of a greater benefit than if you only do business in the domestic market. The results of empirical studies conducted by the European Commission "Internationalization of European SME's" (2010: 8) were carried out on more than $50 \%$ of small and medium enterprises in Europe have resulted in findings "Being international operations strongly do higher growth" which means active internationally firmly to grow more rapidly. SME entrepreneurs realize the importance of building a network, the majority (78\%) of employers say they have a network of SMEs. Networks built with various parties such as purchasers (people), agents, suppliers, trade associations, banks, and the government can support international businesses. By building a network, the SME entrepreneurs to overcome obstacles in carrying out international activities, namely that they can gain access to resources and knowledge as well as access to market opportunities. The importance of the internationalization of the network can be described theoretically using the network model (Flanders 2008: 38) "Small and medium businesses are generally limited by the lack of knowledge and resources in conducting international activities so that in conducting international business need support from partners in the network". In order to successfully build a business network, collaborative relationships based on trust and commitment is an important aspect to keep in touch. SME entrepreneurs can overcome obstacles in carrying out international activities, namely that they can gain access to resources and knowledge as well as access to market opportunities. The importance of the internationalization of the network can be described theoretically using the network model (Flanders 2008: 38) "Small and medium businesses are generally limited by the lack of knowledge and resources in conducting international activities so that in conducting international business need support from partners in the network". In order to successfully build a business network, collaborative relationships based on trust and commitment is an important aspect to keep in touch. SME entrepreneurs can overcome obstacles in carrying out international activities, namely that they can gain access to resources and knowledge as well as access to market opportunities. The importance of the internationalization of the network can be described theoretically using the network model (Flanders 2008: 38) "Small and medium businesses are generally limited by the lack of knowledge and resources in conducting international activities so that in conducting international business need support from partners in the network". In order to successfully build a business network, collaborative relationships based on trust and commitment is an important aspect to keep in touch. The importance of the internationalization of the network can be described theoretically using the network model (Flanders 2008: 38) "Small and medium businesses 
are generally limited by the lack of knowledge and resources in conducting international activities so that in conducting international business need support from partners in the network". In order to successfully build a business network, collaborative relationships based on trust and commitment is an important aspect to keep in touch. The importance of the internationalization of the network can be described theoretically using the network model (Flanders 2008: 38) "Small and medium businesses are generally limited by the lack of knowledge and resources in conducting international activities so that in conducting international business need support from partners in the network". In order to successfully build a business network, collaborative relationships based on trust and commitment is an important aspect to keep in touch.

The results of the research in the first year indicate that the performance of SMEs is not affected by the internationalization variable, meaning that international business activities have not been carried out intensively characterized by the limited scope of operation of the international market and the low level of sales profits. SME performance is affected by network resources' ability to utilize network resources is important for SMEs to access international resources, knowledge, and market opportunities. Internationalization low level and the need for the utilization of network resources, making this study in the second-year concentrates on the manufacture of the modules to be tested on a group of SMEs surveyed, with emphasis of matter related to the knowledge of the creative industry in general and specifically in Kendal District. Knowledge of the Export-Import and knowledge of the Indonesian Export Financing Agency and knowledge about running a business based on digital.

\section{Materials and Methods}

Methods of data collection: Primary data was collected through surveys and interviews with Dinperindagkop Kendal, Kendal Dekranasda, academia, consumer creative industries, and group discussions, while secondary data was collected using documentation. The data collected by contacting the relevant contact person or official/staff.

Sampling Method: The sampling method used to select the creative industry entrepreneurs is purposive sampling, that the creative industry entrepreneurs who have made internationalization and business-oriented to internationalization. The number of samples that participated in this study amounted to 145 SMEs (Small and Medium Industries) of the 245 target population. Respondents involved in this study came from three sectors in the creative industries, namely: fashion, crafts, and furniture. Data were collected from June to August 2019 using a questionnaire.

Respondents creative industry entrepreneurs to interview taken by snowball sampling method or also known as referral chain network. The interview method used is a structured interview method, allowing researchers to obtain data that is wider and deeper, and to the flexibility of the interview process. Then, research data processing is done by using the SEM analysis of covariance matrix input to the maximum likelihood estimation method

\section{Result and Discussion}

This research data processing is done by using the SEM analysis of covariance matrix input to the maximum likelihood estimation method. Before forming a full model SEM, prior testing of the factors that make up each of the variables/constructs using a model of confirmatory factor analysis (CFA) has been done before. Model fit (goodness of fit for confirmatory factor analysis will also be tested. With AMOS program version 23, the test results show the goodness of fit in the output. Conclusions about the suitability of the model created can be seen from the results output goodness of fit obtained.

Having obtained the full model SEM study, further testing is done in conformity with the cut-off value of Goodness of Fit with the results presented in Table 2. Table 2 shows the chi-square test at full research model obtains the results a value of 145.319 under the chi-square tables with a degree of freedom 98 at the 5\% significance level of 212.45 this means that the value of chi-square marginal level research model. A probability value of 0.009 is less than 0.05 which is the threshold probability value is not yet eligible means probability value marginal. However, several other indicators of goodness of fit showed good results, for example, RMSEA smaller than 0:08 $(0,044)$ and TLI value worth 0.97 . 


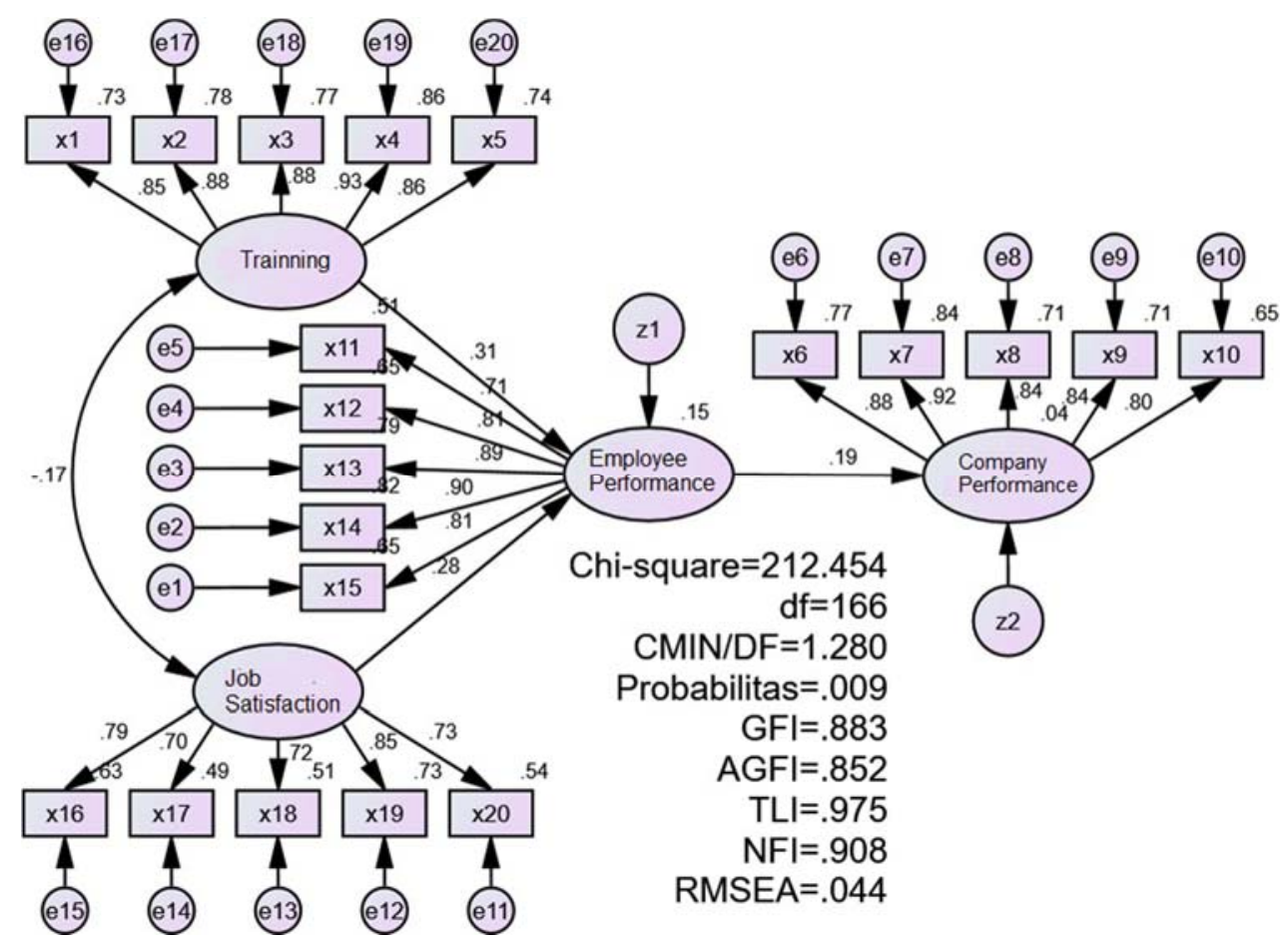

Figure 1 Test Results Full Model Structural Equation Model (SEM)

Table 2. The goodness of Fit Test Results Feasibility Full Model Structural Equation Model (SEM)

\begin{tabular}{lccc}
\hline \multicolumn{1}{c}{ The goodness of Fit Index } & Cut-off Value & Results Model & Information \\
\hline Chi-square & expected small & 212.45 & marginal \\
significance Probability & $\geq 0: 05$ & 0009 & marginal \\
CMIN / DF & $\leq 2: 00$ & $1: 28$ & Fit \\
RMSEA & $\leq 0.08$ & 0044 & Fit \\
GFI & $\geq 0.90$ & 0883 & marginal \\
AGFI & $\geq 0.90$ & 0852 & marginal \\
TLI & $\geq 0.90$ & 0975 & Fit \\
NFI & $\geq 0.95$ & 0908 & marginal \\
\hline
\end{tabular}

Table 3. Summary of Invention Hypotheses

\begin{tabular}{cll}
\hline Hypothesis & Decision & \multicolumn{1}{c}{ Findings } \\
\hline H1 & Received & $\begin{array}{l}\text { Training a positive and significant impact on the performance of } \\
\text { employees }\end{array}$ \\
H2 & Received & $\begin{array}{l}\text { Job satisfaction has a positive influence on employee } \\
\text { performance } \\
\text { Employee Performance positive effect on company performance }\end{array}$ \\
H3 & Received & .
\end{tabular}

\section{Conclusion}

Internationalization of SMEs affected by the ability to utilize network resources. The intensity in the internationalization of SMEs is determined by the ability of the SME entrepreneurs to build partnerships and relationships with partners in the network to overcome the limitations to be able to enter the international market. Build a network with partners such as buyers, suppliers, government, and trade associations to improve understanding of international business. Internationalization is the "Closed Loop" ie, previous experience is a guarantee for the next step. SME entrepreneurs should be able to quickly work in international markets and to prioritize export markets rather than 
the domestic market because of the potential for a larger market.

Performance in SMEs affected by network resources with a strong influence, which means that changes in the performance of SMEs are due to changes in the use of network resources. The ability to utilize network resources is important for SMEs to access international resources, knowledge, and market opportunities, thereby causing a change in the performance of SMEs. It can be concluded, "SME performance in conducting international activities can be formed by a network of capital". The ability to utilize network resources is important for SMEs to access international resources, knowledge, and market opportunities that lead to changes in the performance of SMEs.

Performance is not affected by the internationalization of SMEs. These findings indicate that because of the aspect of "smallness", the intensity of internationalization is still low so it does not have a strong influence on performance. The internationalization level that can be achieved by SME entrepreneurs is still low, which means that international business activities have not been carried out intensively characterized by the limited scope of operation of the international market and the low level of profits and sales.

Internationalization is still low, which showed also knowledge of the Export-Import respondent SMEs is still low. Therefore, in the second year of this research activity conducted by compiling a module of the model Internationalization Training To improve Competitive Advantage. Once the module is compiled, the next step is organizing pieces of training for entrepreneurs/owners of SMEs as many as 145 people. The results of the training are then evaluated by distributing questionnaires related to training, job satisfaction, performance His company respondents and performance. The results of the survey were tested using SEM Test Statistics show that training with the indicator material provided, the method used, the ability of coaches, learning tools.

For implications, this study shows that the use of network resources as a decisive factor to push the level of internationalization and performance. Build and maintain relationships with business partners into a capital network, as it supports access to the resources and knowledge to exploit the opportunities in the international market. For SME entrepreneurs, they should be more active in developing a network with various partners, namely to take the following actions:

1. Improving the use of information and communication technology optimally as a means to build the network. Creating a website on the internet can create a company profile form or online stores making it easier for international buyers to search and find businesses of SMEs and can communicate directly. This method is effective to capture buyers who are not too expensive and difficult to develop SMEs.

2. SME entrepreneurs who are still experiencing difficulties in exporting advised to cooperate with local exporters who have similar products.

3. Opening a business network more widely with various stakeholders such as government (ministries, state-owned companies), associations, private companies, and banks and other financial institutions such as LPEI (Insurance Institution Indonesian exports) so employers SMEs can gain some benefits, namely: (a) fostered partner of SOEs to help facilitate entrepreneurs have a strong business network at an international level; (B) get the opportunity to access capital through nonbanking institutions to finance exports so that they are not fixated on any banking; (C) the opportunity to participate in various training to improve the capacity of business: innovation, quality international standards, technology development, product design, and capacity building of employees; (D) the opportunity to participate in exhibitions both locally and abroad; and (e) be informed about the international market: the profile of buyers, potential overseas markets, and trends in overseas markets.

4. Increase the internationalization of business activities by taking concrete steps as follows: (a) Actively involved in participating in various exhibitions abroad organized by government agencies such as the Ministry of Cooperatives and SMEs, the Ministry of Industry (DG IKM) and the Department of Commerce; (B) take into account aspects of marketing when the exhibition with the aim of promoting the products and invite buyers to visit the stand/booth. The point is the principle of Business to Business (B2B) should be considered not only do retail business. Things that can be done are: pay attention to the design of the stand/booth and layout should be made attractive, the appearance of the product with an interesting composition, actively involved in the exhibition and not only assign employees who have no knowledge of the product.

This study still has limitations, ie capital networks built by entrepreneurs have not 
significantly affected the performance of SMEs. Further research is needed to determine the barriers to SMEs in doing business internationally (export) and how strategies to address the impact on increasing the performance of SMEs. From this research, it was found that the network through the use of capital relations and cooperation with partner build is the dominant factor affecting SME internationalization and performance. The results of this study can be used as a preliminary step to learn more about the internationalization of SMEs based network capital by incorporating other exogenous variables in a concept that has close ties to the level of internationalization, the international knowledge.

Experience is an important basis for the preparation of the expanding business in both the domestic and international markets, as outlined in the European Commission report "Supporting the Internationalization of SME's" (2007: 9) that international orientation is a consequence of experience in the industry in which the company does business. Internationalization is the "Closed Loop" ie, previous experience is a guarantee for the next step.

This research can be developed in the unit of analysis (SME export-oriented) in a wider area by considering the following: (a) By strictly categorize the criteria between group companies in light industry and a group of companies in the media industry because it is based on findings in the field, there are considerable differences in terms of the ability to manage the business. Thus, for further study, respondents targeted for companies in the industry of small and medium industries need to be analyzed differently to get the right profile; (B) Distinguishing SMEs conducting business internationally on the basis of the stages of the process of internationalization, which is between the new SMEs in the early stages with SMEs who have international activities (regular export activities). This is important because of the different business strategies implemented. Based on the findings in the field, SMEs are still in the early stage of internationalization requires more support regarding production capacity, quality, and product design. Inexperienced SMEs, conducting international business is facing more constraints associated with the network and government support to facilitate export procedures and permits.

\section{References:}

[1] Darwis, Yuliandre. 2013. The Urgency of Communication Media (E-Commerce) In Indonesia's Creative Industry as an Effort to Increase International Businesss Competition:
A Case Study of The Fashion Industry. International Journal of Organizational Innovation. Vol 5, No.3.

[2] Dunning, John H. (1993). Multinational Enterprises and the Global Economy, England: Addison-Wesley.

[3] Dessler , Garry . (2015).Human Resource Management ,15 Edition Pearson

[4] Huang, Y., Chen C.J., and Chang H.H. 2008. A multiple criteria evaluation of creative industries for the cultural creativity centre in Taiwan. International Journal of Entrepreneurial Behaviour and Research. Vol. 15 Iss 5 pp 473-496.

[5] Jones, P., D. Comfort, I. Eastwood, and D. Hillier. 2004. Creative Industries: Economic Contributions, Management Challenges and Support Initiatives. Management Research News, Vol. 27 Issue 11/12, 134 - 145.

[6] Luostarinen, R. and Hellmann, H. (1994). The internationalization Processes and Strategies of Finnish Family Firms. CIBR Research Papers, Helsinki: School of Economies and Business Administration.

[7] Luthans,F (2011), Organizational Behavior: An Evidence-Based Approach

[8] Ferdinand, A. (2014). Management Research Method: a research guidance for writing thesis and dissertation in management science. Semarang, Undip Press - Badan Penerbitan Undip..

[9] Raymond, A Noe . (2016). Employee Training And Development ,Seventh Edition .McGraw Hill Education

[10] Robbins Steven and Judge . (2015). Organizational Behaviour ,16 Edition .Pearson

[11] Versus Non-Partisipatory Training on Micro Small Medium Enterprises (MSMES). International Business and Management. Vol: 10. No: 4 pp: 534-539

[12] Swords, J. and Wray, F. (2010) "The Connectivity of the Creative Industries in North East England - The Problems of Physical and Relational Distance" Local Economy, 25 (4), 305 - 318

[13] Thompson, Arthur. A, A.J. Strictland and John Gamble. 2010. Crafting and Executing Strategy: The Quest for Competitive Advantage. McGraw-Hill. 